DIW BERLIN

Discussion Papers

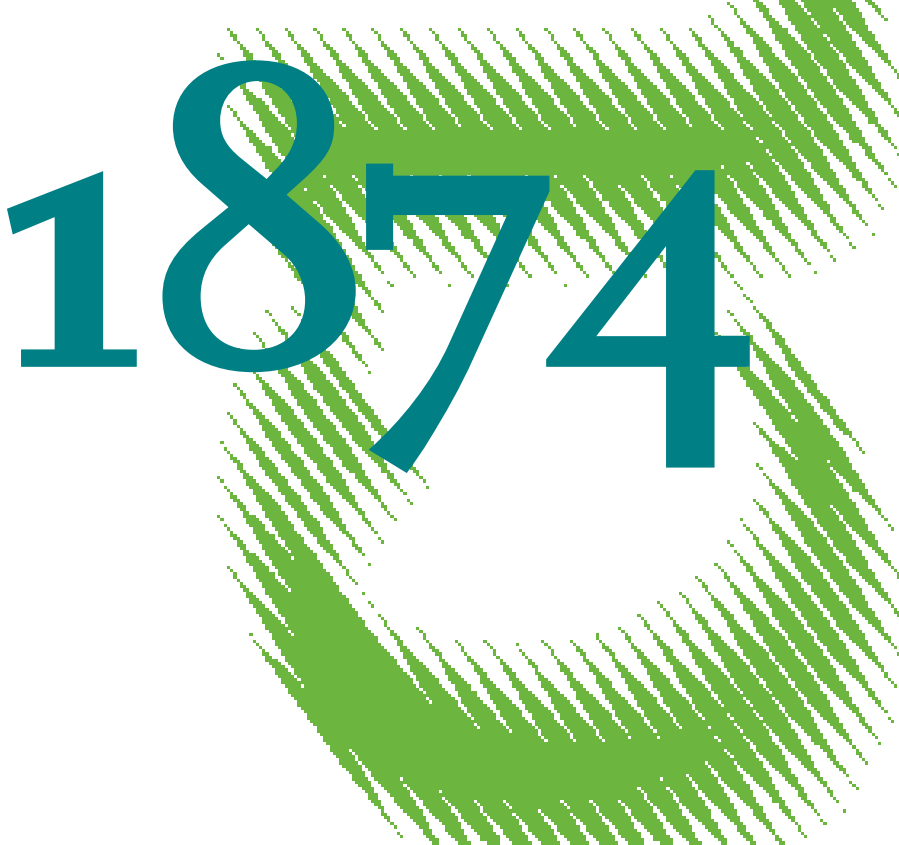

Distributional Effects of the COVID-Ig Lockdown 
Opinions expressed in this paper are those of the author(s) and do not necessarily reflect views of the institute.

IMPRESSUM

(C) DIW Berlin, 2020

DIW Berlin

German Institute for Economic Research

Mohrenstr. 58

10117 Berlin

Tel. +49 (30) $89789-0$

Fax +49 (30) $89789-200$

http://www.diw.de

ISSN electronic edition 1619-4535

Papers can be downloaded free of charge from the DIW Berlin website:

http://www.diw.de/discussionpapers

Discussion Papers of DIW Berlin are indexed in RePEc and SSRN:

http://ideas.repec.org/s/diw/diwwpp.html

http://www.ssrn.com/link/DIW-Berlin-German-Inst-Econ-Res.html 


\title{
Distributional effects of the COVID-19 lockdown
}

\author{
Marius Clemens, Maik Heinemann ${ }^{\dagger}$
}

June 10, 2020

\begin{abstract}
A two-sector incomplete markets model with heterogeneous agents can be used to study the distributional effects of the COVID-19 lockdown. While negative aggregate welfare effects of the lockdown are unavoidable, the size of aggregate welfare effects as well as the distribution of the welfare effects across agents turn out to depend on the specific economic environment of the affected economy as well as the response of the government to the shock. We use the model to simulate the lockdown effects based on a calibration to German data.

First, we find that without state aid and limited access to international financial markets especially poor household suffer large welfare losses, while wealthy household could even benefit from the lockdown.

Second, a state aid program reduces large parts of the welfare losses of workers across all income groups in the affected sectors by forcing loss sharing with agents working in the non-affected sector. However, wealthy households no matter in which sector still benefit more than the average household.

Third, access to international financial markets is key to shift relative welfare gains from superrich to poorer households in both sectors. Once the country is able to borrow internationally, the benefit for superrich diminishes.

Our results implicate that countries with rather limited access to financial markets and less stable government budget positions will suffer higher welfare losses and increases in inequality.
\end{abstract}

JEL-Classification: D31, E21, E62, I14

Keywords: COVID-19, Income and Wealth Inequality, Heterogeneous Agents, Fiscal Policy

*DIW Berlin, BERA. E-mail address: mclemens@diw.de.

†University of Potsdam. E-mail address: maik.heinemann@uni-potsdam.de. 


\section{Motivation}

Since the outbreak of COVID-19 contributions to macroeconomic issues of pandemics has emerged exponentially, many of them collected in Baldwin and di Mauro (2020) and CEPR (2020) series.

Viral shocks can be disentangled into a pure health component that mainly affects labour supply depending on the capacities in the health sector and a lockdown component which consists of the containment policies in order to protect the citizens. ${ }^{1}$ From an economic perspective the latter is clearly relevant. Eichenbaum, Rebelo, and Trabandt (2020a) show that a social optimal containment policy increases the severity of the recession. ${ }^{2}$ Krueger, Uhlig, and T. (2020) extend the original Macro-SEIR model by different sectors, and show that the severity of the economic crisis in this setup can be much smaller. Guerrieri et al. (2020) present a theory of Keynesian supply shocks which lead to excessive demand disruptions, larger than the supply-side shock itself. They argue that shutdowns, layoffs and firm exits have strong effects if markets are incomplete and the economy has more than one sector.
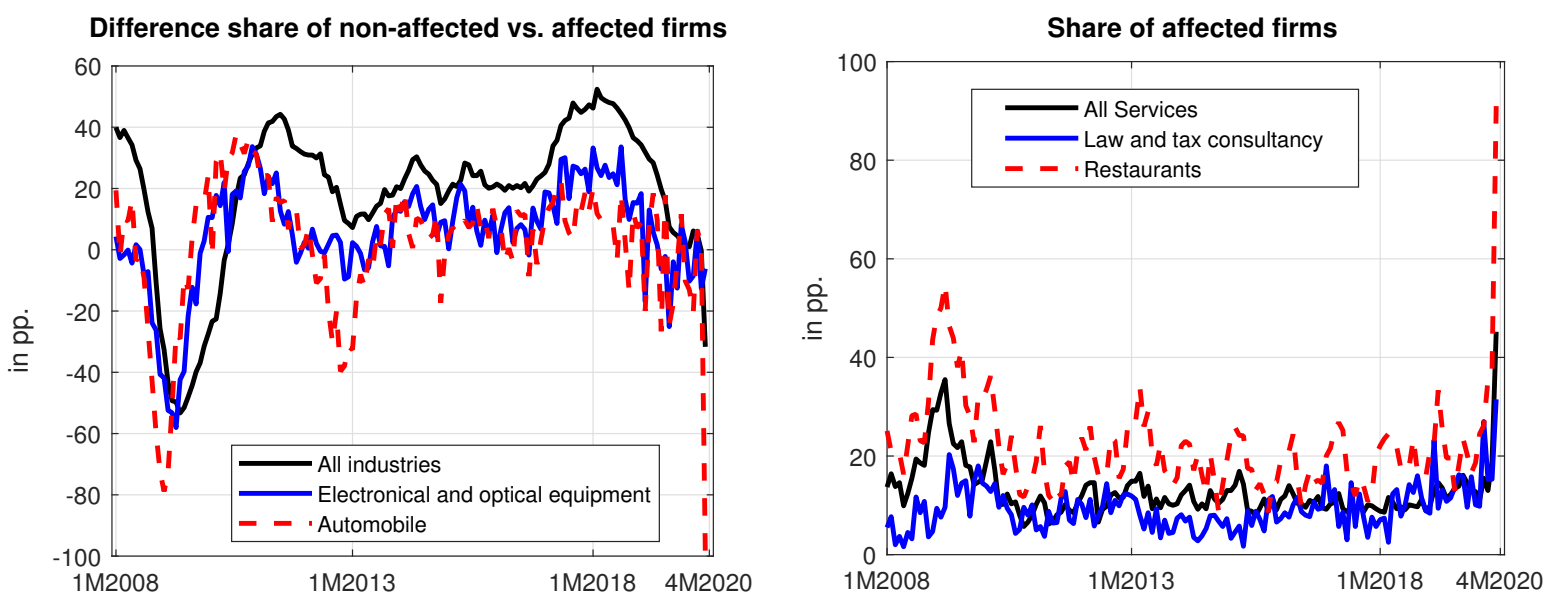

Figure 1: Affected vs. non-affectd firms - Germany 1M2008-4M2020 Source: ifo Institute (2020)

First evidence from Germany shows how large the economic effects of a partial lockdown can be. The share of firms that face negative production developments in the industry sector increased recently. The black line in figure 1 (left graph) depicts the balance between positive and negative answers within the monthly ifo business climate survey. ${ }^{3}$ In January 2018, the share of firms with good production development was 40 percentage points higher than those with a negative one (black line). Due to the

\footnotetext{
${ }^{1}$ See Atkeson (2020), Kholodilin and Rieth (2020).

${ }^{2}$ In their paper they combine the canonical epidemiological model (SEIR) with a stylized macroeconomic model where households decide about consumption and work considering infection rates. In a follow-up paper Eichenbaum, Rebelo, and Trabandt (2020b) use their Macro-SEIR model also to investigate the role of testing and quarantining and find that testing combined with quarantining infected people has large social benefits.

${ }^{3}$ See ifo Institute (2020). While in the service sector there are data available for the share of firms that
} 
lockdown in April 2020, this value switched to $-20 \mathrm{pp}$. and thus to a $20 \mathrm{pp}$. higher share of firms who face negative production development. However, because the value does not reach 100 percent, it also reflects that firms are differently affected. By looking at two specific branches we see how large those differences could be. Within the automobile branch (red dotted) almost every firm, who participates at the survey, is negatively affected. On the other hand, the branch of electronic and optical equipment (blue line) seems not to be harmed as a whole, because within the branch affected and non-affected firms compensate each other. A similar picture can be drawn in the service sector (see right graph Figure 1): Here, the overall share of affected firms (black line) has increased strong than in the financial crisis. Some branches, e.g. restaurants (red dotted) are strongly affected, others, e.g. (lawyer and tax consultancies) (blue) are less affected.
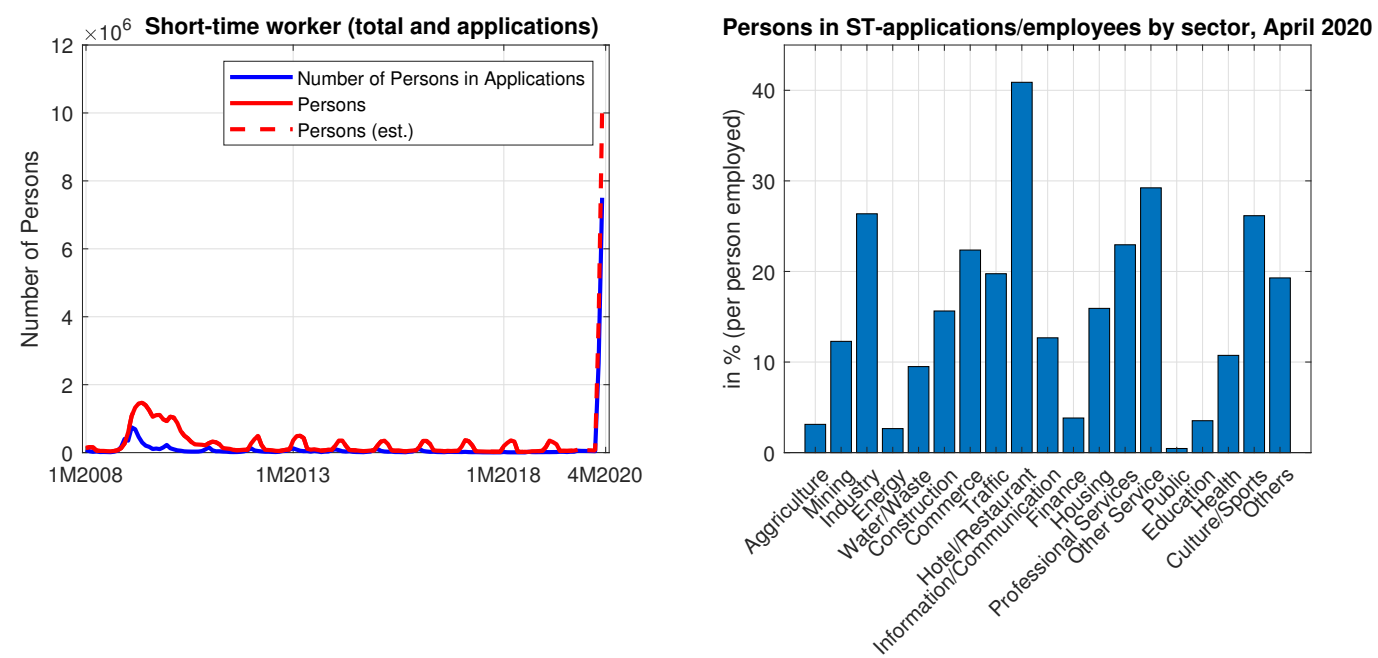

Figure 2: Short-time work and government direct compensation - Germany 1M2008$4 M 2020$

Source: Federal Employment Agency (2020)

This heterogeneous effects across branches of the COVID-19 shock translate to households wage income inequality. In Figure 2 (left graph) the actual numbers of short-time workers is depicted together with the number of persons in applications for short-time work for April 2020. Here, we see that due to the COVID-19 shock, applications already in March, where the lockdown started, increased up to 2.5 million, already higher as in the financial crisis 2009. However, in April additional 7.5 million persons in applications were counted, summing up to 10 million expected short-time worker. The heterogeneity across branches is depicted in Figure 2 (right graph). It shows the additional number of persons in applications for short-time work in April 2020 subtracted by the numbers in February 2020. Thus, it is a proxy for the COVID-19-related short-time worker per branch, normalized by the total number of employees per branch end of 2019. The picture confirms our former evidence also for workers and households: In some sectors, e.g. hotel and restaurant, industry, culture and sports, a large share of face negative production development, in the industry sector we have only data for the difference/balance between the share of positive and negative answers. 
workers is affected, while in others, e.g. finance, public services, energy they are rather not.

In order to dampen the negative economic and distributive effects of the economic lockdown, the German government has provided direct transfers to firms and households: ${ }^{4}$ First, they introduced changes in the law for short-time work payments. Now between 60 and 87 percent of the wage including social contributions depending on the family status and the duration of short-time work ("Kurzarbeitergeld") will be paid. Second, they take over transfers to small business cover fix costs for e.g. rental fees by roughly 60 billion Euro ("Solidaritätsfonds"). Third, firms got additional liquidity provisions by tax deferrals of around 20 billion Euro. ${ }^{5}$

Although, clearly the whole economy is hit negatively by the COVID-19 shock, the stylized facts point towards large distributional effects. From medical studies, we already know that the health component of the COVID-19 shock mainly affects old persons and those with underlying health conditions. ${ }^{6}$ However, from a macroeconomic perspective the distributional effects of an economic lockdown are still rather unexplored. Bayer and Kuhn (2020) combine medical with socio-economic data and analyze the relationship of the case-fatality rate and the cross-country differences in living arrangements within families. Glover et al. (2020) study the optimal mitigation policy in a rich heterogeneous agent model by age, sector and health status for the USA. They find that optimal redistribution and mitigation policies interact and reflect a compromise between diverging preferences of subgroups. Kaplan, G. and Moll, B. and Violante, G. (2020) combine an epidemiological model (SEIR) with a HANK model where agents differ by the degree of social consumption and how easy they can work from home. Bayer et al. (2020) also use a HANK model for analyzing the distributive effects of COVID-19 shocks and the transfer multiplier in the USA. They find that the income risk in the USA has sharply risen but that the large transfer stimulus mitigated the income risk. The multiplier for conditional transfers in the USA ranges between 1 and 2. Furceri et al. (2020) find that major past pandemics have led to increases in the Gini coefficient, raised the income shares of higher income deciles, and lowered the employment-to-population ratio for those with basic education compared to those with higher education. Furthermore, they provide evidence that distributional consequences from the current COVID-19 pandemics will presumably become even larger.

In our paper we contribute to this literature by analyzing the distributional effects of lockdown shocks and welfare effects of compensatory measures of the government. Thereby, we combine the two-sector lockdown economy of Guerrieri et al. (2020) in an incomplete markets model à la Aiyagari (1994). The ultimate aim is to derive the welfare effects for different households distinguished by the affected and the non-affected sectors and compare different scenarios: a pure shutdown scenario and a state aid scenario,

\footnotetext{
${ }^{4}$ Furthermore, the German government has increased the guarantee framework for credits ("Credit Bazooka") by 553 billion Euro for all firms and extra 400 billion guarantees and 200 bn credit only for large firms ("Wirtschaftsstabilisierungsfonds"). For small and medium-size firms they provide fast credits ("'KfW Schnellkredit").

${ }^{5}$ See tax estimation Mai 2020 by Working Party on Tax Revenue Estimates (2020)

${ }^{6}$ See Ferguson, N. M. et al. (2020).
} 
both in a closed and in an open economy setting.

In a first step we calibrate the model to German data and simulate assuming a one month lockdown in the relevant sector plus immediate return to normality. In a second step we analyze the distributional effects of the COVID-19 shock for the different scenarios.

We find that after economic lockdown shocks, poor households loose the most and rich household could even make welfare gains. ${ }^{7}$ By providing money to affected sectors, i.e. in Germany "Kurzarbeitergeld" and "Solidaritätsfonds", the government reduces inequality and welfare costs. However, from state aid programs, households at the top end of the wealth distribution, no matter in which sector they work, benefit stronger than the middle-income household.

Finally, we compare the closed economy benchmark, where government debt is held only by unconstrained agents (richer households) with the small open economy case, where external debtors can jump in and buy government debt. Here, we find that the distributive effects become smaller, because internationally the interest rate reaction due to increased debt is zero. From the German perspective these are good news, because the German financial situation is stable and government bonds are bought for safe heaven motives. However, from the perspective of countries that have less generous social systems or even no access to international financial market, our results point to strong distributive and negative welfare effects of a lockdown. This speaks in favor of common permanent stabilization instruments and debt mechanisms at the European level.

The remainder of this paper is structured as follows. The second section presents the two-sector incomplete markets model, the equilibrium conditions, a definition of the welfare function, a description of the scenarios and the model calibration. In the third section the baseline results of a 'closed economy' without state aid are discussed and compared with those of alternative scenarios 'with state aid' and in an 'open economy' setup. The section ends up with a parameter robustness analysis. The fourth section then concludes.

\section{The two sector model with heterogeneous agents}

\subsection{Model assumptions and solution}

We consider a standard incomplete markets model à la Aiyagari (1994) with two consumption goods produced in two different sectors under constant returns to scale. The economy is populated by a continuum of agents with unit mass which are subject to idiosyncratic productivity risk. Individual productivity $\theta$ follows an $s$ state Markov process with transition matrix $P$ and state vector $\Theta=\left(\theta_{1}, \ldots \theta_{s}\right)$. Without loss of generality it is

\footnotetext{
${ }^{7}$ The result is mainly driven by large initial interest rate effects that are triggered by the lockdown. These effects tend to harm poorer agents while favoring the richer. However, the introduction of physical capital and capital risk would dampen that effect.
} 
assumed that $\mathrm{E}[\boldsymbol{\theta}]=1$ such that aggregate labor supply — in efficiency units — is always equal to one.

Agents consume two kinds of goods $c_{1}$ and $c_{2}$. The intratemporal utility function of an agent is given by:

$$
u\left(c_{1}, c_{2}\right)=\frac{1}{1-\rho}\left(\gamma c_{1}^{\mu}+(1-\gamma) c_{2}^{\mu}\right)^{(1-\rho) / \mu}
$$

Here $\mu$ determines the elasticity of substitution between the two goods which is given by $\frac{1}{1-\mu}$. For reasons that will be described later, we assume that this elasticity is greater than one, which implies $0<\mu<1$.

The two goods are produced under conditions of perfect competition. There are two sectors of production. Each sector produces only one type of good and the production functions for the two goods are given by $z_{i}=A_{i} n_{i}$, for $i=1,2$ where $z_{i}$ denotes output of good $i$ and $n_{i}$ employment in sector $i$. $A_{i}$ denotes total factor productivity in the production of good $i$ and because of the assumptions regarding the production functions, the price $p$ of $c_{2}$ good in units of $c_{1}$ is given by where $p=A_{1} / A_{2}$. We start with a situation where labor is perfectly mobile across sectors of production. Thus, perfect competition and perfect labor mobility across sectors implies that the wage rate $w$ equals $A_{1}=p A_{2}$.

Agents can hold and trade a riskless asset in order to smooth consumption. The riskless asset is in zero net supply and agents are subject to a borrowing limit which requires individual asset holdings $a(i)$ to be greater than the debt limit $-\phi$ in all periods.

In each period, every agent allocates his total consumption expenditures $y$ in order to maximize utility. The solution to this static optimization problem can be summarized as follows:

$$
\begin{aligned}
y & =c_{1}+p c_{2} \\
c_{1} & =y(1+\Omega(p) p)^{-1}, \\
c_{2} & =y \Omega(p)(1+\Omega(p) p)^{-1},
\end{aligned}
$$

where $\Omega(p)=\left(p \frac{\gamma}{1-\gamma}\right)^{-\frac{1}{1-\mu}}$.

Given this solution for expenditures, the utility of an agent can be expressed by the following indirect utility function:

$$
u\left(c_{1}, c_{2}\right)=\frac{1}{1-\rho}(y \Gamma(p))^{1-\rho} \equiv U(y ; p)
$$

where $\Gamma(p)=(1+\Omega(p) p)^{-1}\left(\gamma+(1-\gamma) \Omega(p)^{\mu}\right)^{\frac{1}{\mu}}$.

The intertemporal optimization problem of an agent with asset holdings $a$ and current productivity $\theta$ is thus described by the following Bellman equation (where we use primes $\therefore$ - to denote next period values):

$$
V(a, \theta)=\max _{a^{\prime} \geq-\phi} U\left(a+w \theta-a^{\prime} q ; p\right)+\beta \mathrm{E}_{\theta^{\prime}} V\left(a^{\prime}, \theta^{\prime}\right) .
$$


Here $q$ is the price of next-period credit balances (cf. Huggett (1993)). The solution to the Bellman equation (3) is characterized by an optimal 'consumption function' $y(a, \theta)$ and a corresponding function describing next periods' asset holdings $a^{\prime}(a, \theta)=$ $(a+w \theta-y(a, \theta)) / q$. The optimization problem can be solved numerically using standard techniques. We solve for this function by first defining $\hat{a}=a+\phi$ and then iterating the first order condition (i.e. the Euler equation) resulting from the above stated Bellman equation (for a given values of $q$ ) using the endogenous grid point method of Carroll (2005):

$$
\begin{aligned}
y(\hat{a}, \theta) & \leq\left(\beta \frac{1}{q} \mathrm{E}_{\theta^{\prime}}\left[y\left(\hat{a}^{\prime}, \theta^{\prime}\right)\right]^{-\rho}\right)^{-1 / \rho} \\
& =\min \left[R a+w \theta+(q-1) \phi,\left(\beta R \mathrm{E}_{\theta^{\prime}}\left[y\left(\hat{a}^{\prime}, \theta^{\prime}\right)\right]^{-\rho}\right)^{-1 / \rho}\right],
\end{aligned}
$$

where $y\left(\hat{a}^{\prime}, \theta^{\prime}\right)=y\left(\hat{a}+w \theta+(q-1) \phi-y(\hat{a}, \theta), \theta^{\prime}\right)$. Whenever $y(\hat{a}, \theta)$ is known, the demand functions $c_{1}(\hat{a}, \theta)$ and $c_{2}(\hat{a}, \theta)$ for the two goods follow from (1a) - (1c).

Given the Markov process for the individual productivity states, the optimal consumption function allows for the computation of the stationary distribution of wealth across agents or, put differently, for the stationary joint distribution $f(a, \theta)$ of assets and productivity states. This distribution and its mean $\mathrm{E}\left[a^{\prime}\right]=\int_{(a, \theta)} a^{\prime}(a, \theta) d f(a, \theta)$ depends on the asset price $q$. A stationary equilibrium is therefore characterized by an asset price $q^{*}$ that implies $\mathrm{E}\left[a^{\prime}\right]=0$. Such stationary equilibrium then also implies a specific allocation of labor across the two sectors of production. In what follows, $n_{1}$ denotes employment in the first sector, while $n_{2}=1-n_{1}$ denotes employment in the second sector.

\subsection{Static equilibria with and without a lockdown}

The initial situation without a lockdown is an equilibrium where labor is mobile across sectors of production. Consequently, perfect competition and labor mobility across both sectors implies that there is a uniform wage $w^{*}$ expressed in units of good 1 that is given by $w_{1}=w_{2}=w^{*}=A_{1}=p^{*} A_{2}$, where $p_{1}=p_{2}=p^{*}=A_{1} / A_{2}$ is the price of good 2 expressed in units of good 1. Via (1b) and (1c), the equilibrium price $p^{*}$ then determines employment in both sectors:

$$
\begin{aligned}
& \frac{c_{2}^{*}}{c_{1}^{*}}=\frac{n_{2}^{*} A_{2}}{n_{1}^{*} A_{1}}=\Omega\left(p^{*}\right)=\Omega\left(A_{1} / A_{2}\right) \\
\Rightarrow & \frac{n_{1}^{*}}{n_{2}^{*}}=\left(\frac{\gamma}{1-\gamma}\right)^{-\frac{1}{1-\mu}}\left(\frac{A_{1}}{A_{2}}\right)^{-\frac{\mu}{1-\mu}} .
\end{aligned}
$$

In case of a lockdown, productivity in sector 2 drops to $A_{2}^{\prime}<A_{2}$. As we assume that employment in the two sectors is fixed to the respective pre-lockdown values, now (5) 
can be used to compute the price $p_{2}^{\prime}$ of good 2 that is compatible with market clearing:

$$
\begin{aligned}
\Omega\left(p_{2}^{\prime}\right) & =\frac{n_{2}^{*} A_{2}^{\prime}}{n_{1}^{*} A_{1}} \\
\Rightarrow \quad p_{2}^{\prime} & =\left(\frac{n_{2}^{*} A_{2}^{\prime}}{n_{1}^{*} A_{1}}\right)^{\mu-1} \frac{1-\gamma}{\gamma} .
\end{aligned}
$$

Thus, because $\mu<1$ the drop in productivity always causes an increase in the price of good 2. However, as the wage rate in the second sector is now given by $w_{2}^{\prime}=p_{2}^{\prime} A_{2}^{\prime}-$ while the wage in the first sector remains at the level $w_{1}=w^{*}=A_{1}$ - the wage in this sector decreases if and only if $0<\mu<1$, i.e. if the elasticity of substitution between the two goods is greater than one. Thus, only in this case the employees in the sector affected by a lockdown experience a drop in their wages. ${ }^{8}$

\subsection{Computation of welfare effects}

We compute welfare effects in a standard manner, as a percentage increase in consumption that is necessary to compensate agents for being exposed to a lockdown. Specifically, we start from the indirect utility function (2) and ask for the percentage increase in consumption $y(i)=c_{1}(i)+p c_{2}(i)$ expressed in terms of good 1 . With $V(a, \theta)_{0}$ denoting lifetime utility of an agent characterized by asset holdings $a$ and productivity $\theta$ in the initial situation and $V(a, \theta)_{1}$ denoting lifetime utility of the same agent in a situation with a lockdown, the individual welfare effect $\Delta(a, \theta)$ is computed as:

$$
\Delta(a, \theta)=\left[\left(V(a, \theta)_{1} / V(a, \theta)_{0}\right)^{\frac{1}{(1-\rho)}}-1\right] \times 100 .
$$

Thus, $\Delta(a, \theta)$ is the percentage increase in consumption an agent characterized by $(a, \theta)$ requires in the baseline a situation without a lock down to attain the same lifetime utility as in a situation with a lock down. Consequently, $\Delta(a, \theta)<0$ means that this agent suffers a welfare loss due to a lock down .

Based on individual welfare effects, the aggregate welfare effect $\bar{\Delta}$ is computed as: ${ }^{9}$

$$
\bar{\Delta}=\frac{\int_{(a, \theta)} \Delta(a, \theta) y(a, \theta)_{0} d f(a, \theta)}{\int_{(a, \theta)} y(a, \theta)_{0} d f(a, \theta)}=\int_{(a, \theta)} \Delta(a, \theta) y(a, \theta)_{0} d f(a, \theta) .
$$

Thus $\bar{\Delta}$ represents the percentage increase of aggregate consumption of the clean good necessary in the baseline situation without a lock down as a compensation for not being exposed to such a lock down. Hence, $\bar{\Delta}<0$ implies that the society as a whole suffers a welfare loss from a lock down.

\footnotetext{
${ }^{8}$ With $\mu<0$, the increase in the price of good 2 turns out to be that large that the wages in this sector in fact increase in case of a lockdown.

${ }^{9}$ Average consumption in the initial situation equals the wage rate, which is assumed to be equal to one.
} 


\subsection{Alternative setups}

We consider two different setups: The first one assumes that the riskless asset is in zero net supply throughout the entire time period including and following the lockdown. We label this the 'closed economy' setting as there exists no third party from which the agents in our economy could borrow (or lend to). The second scenario then assumes that such a third party exists and this scenario is therefore labeled the 'small open economy' setting. ${ }^{10}$

Within both setups we compare the effects of a lockdown shock without any reaction of the government ('no state aid') with a situation, where the government counterbalances the wage losses of the employees in the affected sector by transfer payments ('state aid program'). For this state aid program, we assume that the government pays transfers to the agents employed in the affected sector that compensate for the income losses compared to the agents employed in the non-affected sector. Thus, total transfers during each period of the lockdown amount to $n_{2}^{*}\left(w^{*}-w_{2}^{\prime}\right)$. These transfers are financed via government debt. We assume that government debt is zero in the initial equilibrium. Therefore, in each period $t=0,1, \ldots$ the lockdown lasts, government debt $b_{t}$ evolves according to:

$$
q_{t} b_{t+1}=b_{t}+n_{2}^{*}\left(w^{*}-w^{\prime}\right), \quad b^{*}=b_{0}=0
$$

After the lockdown, the government levies in each period $t$ a proportional labor income $\operatorname{tax} \tau_{t}$ to bring government debt back to its initial level. To keep things simple we assume that taxes are set according to the following rule: ${ }^{11}$

$$
\tau_{t}=\psi b_{t} / w^{*}
$$

Here $\psi$ is a parameter that governs the speed at which government debt after the lockdown converges back to its initial level $b^{*}=0$. Given this rule, the dynamics of government debt are given by:

$$
b_{t+1}=\frac{1-\psi}{q_{t}} b_{t}
$$

Hence, as long as $\psi>1-q_{t}$ for all $\mathrm{t}, b_{t}$ converges to zero as $t \rightarrow \infty$.

\subsection{Calibration and steady state}

In order to simulate the model at a monthly frequency, we recalculate quarterly values from standard DSGE models and use empirical observations for Germany. Thus, we set the time preference factor $\beta$ equal to 0.99 which corresponds to 2.75 percent annualized interest rate. The standard deviation $\sigma_{u}$ and the persistence $\rho_{\theta}$ of the idiosyncratic shock are set to 0.15 and 0.96 in order to match the observed stationary income distribution,

\footnotetext{
${ }^{10}$ It has to be noted that we interpret the open economy results from the financial balance perspective. Inversely, it could be also argued along the trade balance perspective, assuming that the good produced by the unaffected sector is a tradable good while the good produced by the affected sector is nontradable. In that case, we would see net imports of the tradable good due to relative price changes.

${ }^{11}$ Notice that the wage in both sectors is again $w^{*}$ after the lockdown
} 
measured by the Gini index. Intratemporal and intertemporal elasticities of substitutions $\mu$ and $\rho$ are set to 1.5 and to 1 . We normalize the productivity levels of both sectors $\left(A_{1}\right.$

Table 1: Model parameters

\begin{tabular}{lcc}
\hline Parameter & Notation & Target \\
\hline Time preference & $\beta=0.99$ & Annualized interest rate 2\% \\
Standard dev. idiosyncratic prod. & $\sigma_{u}=0.15$ & Gini index 0.27 (after tax) \\
Persistence idiosyncratic prod. & $\rho_{\theta}=0.96$ & Gini index \\
Consumption share NA sector & $\gamma=0.59$ & Table 3 \\
Relative utility & $\mu=0.33$ & Elasticity of intratemporal substitution 1.5 \\
Elasticity Intertemporal Substitution & $\rho=1.01$ & Relative risk aversion \\
\hline Lockdown \& stabilization policy & & \\
\hline Productivity NA sector & $A_{1}=1$ & Normalized to 1 \\
Productivity A sector (normal) & $A_{2}=1$ & Relative productivity to NA sector \\
Productivity A sector (lockdown) & $A_{2}^{\prime}=0.3$ & Quarterly production loss Table 4 \\
Lockdown duration & $t_{l}=1$ & Average duration of affected firms \\
Debt elasticity of tax & $\psi=0.05$ & Duration debt consolidation 5 years \\
Household debt limit & $\phi=5$ & $\bar{b}=5$ \\
\hline
\end{tabular}

and $A_{2}$ ) to one and calibrate the consumption share of the non-affected sector $\gamma=0.59$ based on the most recent input output table for the German economy. ${ }^{12}$ Once the lockdown starts, the productivity in the affected sector $A_{2}^{\prime}$ decreases by 70 percent to 0.3 , which is in line with recent estimates for quarterly production losses of affected sectors between 10 and 25 percent and around 10 percent for the total economy. ${ }^{13}$ The lockdown duration is set to $t_{l}=1$ which reflects the number of months firms in the affected sectors face productivity losses. In our baseline calibration, we assume that the lockdown shock is a unique event in order to isolate the effects of one-month economic lockdown. Thus, by assumption the most affected firms are getting back to normal after one month. In table 2 of the robustness subsection 3.3 we include the effects of longer and more restrictive lockdown periods on GDP growth and the debt-to-GDP ratio in order to analyze the driving forces of growth and welfare differences. ${ }^{14}$ Finally, we set the debt elasticity of tax $\psi$ equal to 0.05 . An increase of debt by one Euro leads to a tax increase for non-affected households in the next period by 0.05 Euro.

\footnotetext{
${ }^{12}$ See Destatis (2020) and Table 3 in appendix.

${ }^{13}$ See Table 4 in appendix.

${ }^{14}$ We then include also specifications that are more in line with recent empirical projections. In Germany, the shutdown of the economy was proposed to start from 18 March 2020. A first easing process started in the end of April 2020. Although many firms reopened their businesses, strongly affected, i.e. restaurants, travel agencies, sports still face the lockdown. See German Economic Research Institutes (2020), German Council of Economic Experts (2020), IMF (2020).
} 


\section{Results}

\subsection{A partial lockdown in a 'closed economy'}

The negative supply reaction initialized by the partial lockdown has two main effects: First, wages in the affected sector decrease due to the reduced labor productivity. Second, the price of the good produced by the affected sector increases in order to equate the demand for this good to the now reduced supply.

While agents employed in the first sector are only affected by this latter effect, agents employed in the second sector also experience lower wage incomes when 'no state aid' appears. Certainly, confronted with this shock all agents want to smooth their consumption, but agents employed in the affected sector have a stronger motive to do so. Finally, because the riskless asset is in zero net supply the agents employed in the non-affected sector will end up as creditors of the agents employed in the affected sector. In order to induce the agents working in the non-affected sector to hold as a whole a positive asset position, the interest rate has to rise, at least under the usual assumption regarding the intertemporal elasticity of substitution (see Figure 3). ${ }^{15}$
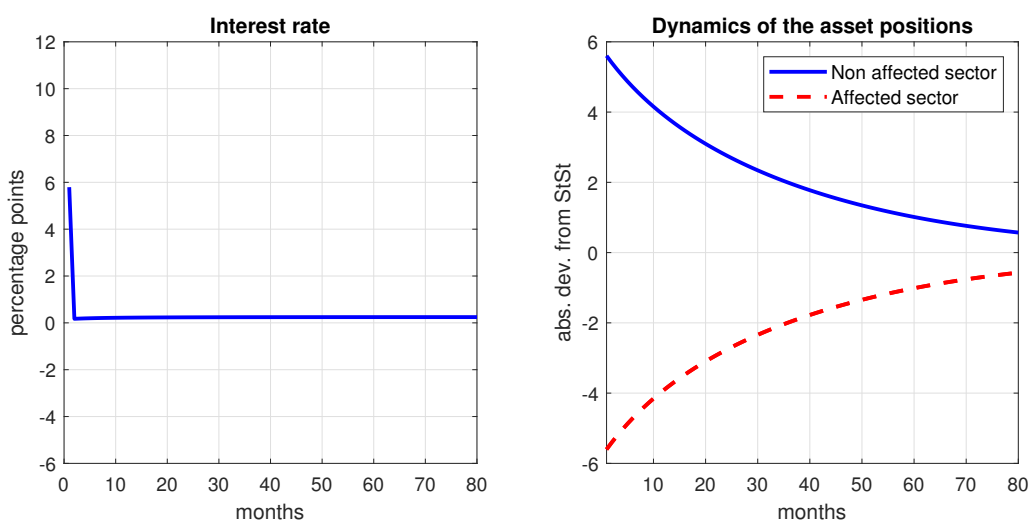

Figure 3: Interest rate and asset positions after a partial lockdown in a 'closed economy' and 'no state aid' (baseline)

We now assume that the government tries to compensate the negative economic effects of the shutdown by introducing a 'state aid program' financed by issuing new debt. Thus, in our baseline scenario with one month lockdown the debt-to-GDP ratio increases by 12 percentage points on a monthly base in order to compensate the employees in the affected sector for their wage losses. ${ }^{16}$ After the lockdown, government debt is reduced back to its former level by taxing labor income (see Figure 4 left).

In the 'closed economy' the private sector as a whole has to hold a positive asset position that mirrors the time path of government debt. As before, this requires an increase of the interest rate which turns out to be larger than in the situation without a government reaction (see Figure 4 right).

\footnotetext{
${ }^{15}$ Additionally, a large part of the interest rate increase is attributable to an intertemporal equilibrium effect that similarly arises in an economy with homogeneous agents. c.f. Guerrieri et al. (2020).

${ }^{16}$ This corresponds to an annual increase of 1.2 percentage points.
} 

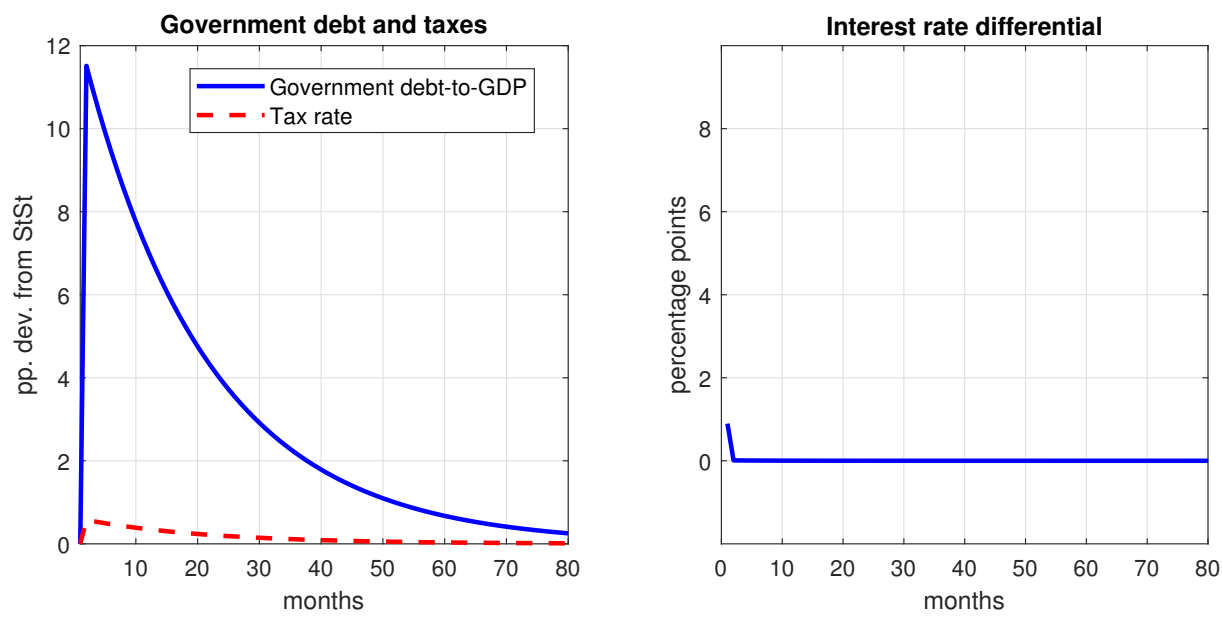

Figure 4: Government debt-to-GDP and labor tax rate (left) and interest rate differential (right) after a partial lockdown in a 'closed economy' with 'state aid program'

Regarding the welfare effects some results are noteworthy (left graph figure 5): First, the welfare losses due to the partial lockdown are larger for less wealthy agents no matter if the government helps or not. Borrowing households, i.e. households with a negative asset position, suffer a welfare loss that equals between -0.5 and -1.5 percent of their steady state consumption. Second and not surprisingly, the negative impact of a partial lockdown is larger for the employees of the affected sector (blue dashed line). Third, due to the increased interest rate, very rich agents even gain from a partial lockdown. Fourth, government financial aid tends to mitigate the negative welfare effects for poor agents (red dashed line). However, due to the stronger increase of the interest rate in case of 'state aid program' relative to 'no state aid', the welfare gains of the rich agents turn out to be even larger once the government provides financial aid.

Aggregated over all agents, the 'state aid program' in the baseline scenario with only
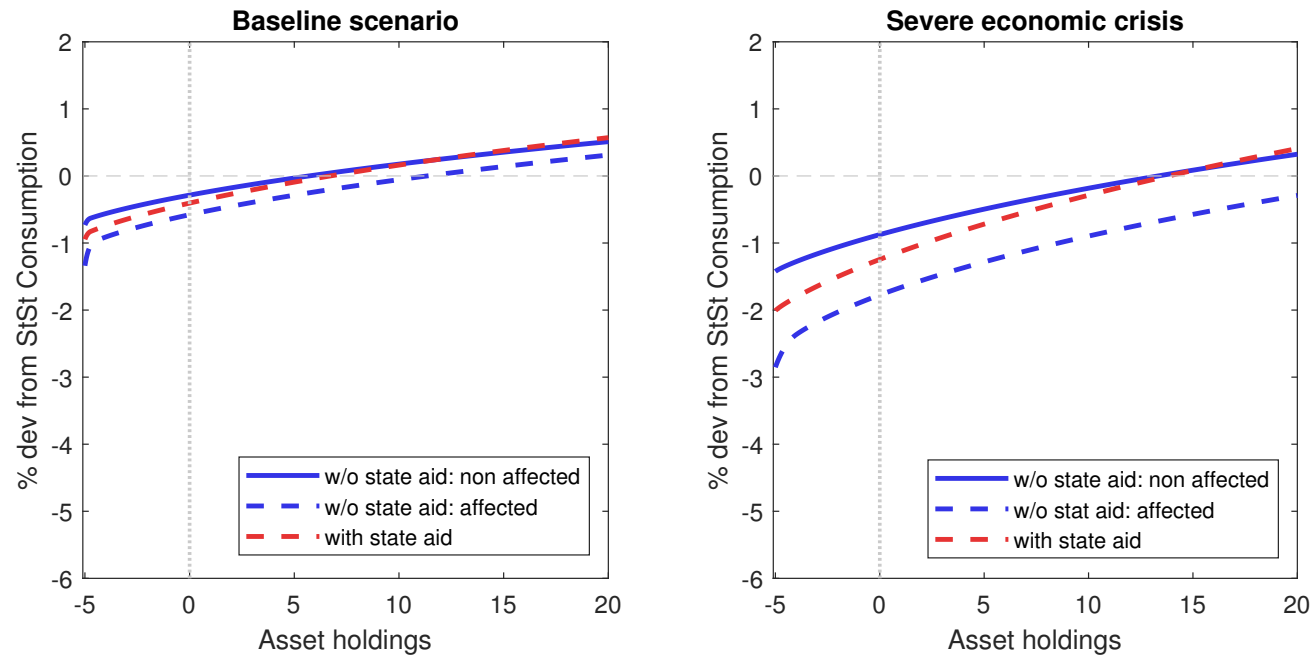

Figure 5: Welfare effects of a partial lockdown in a 'closed economy', baseline calibration (left) and severe economic crisis calibration (right) 
one month lockdown dampens aggregate welfare loss by roughly 8 percent converted in steady-state consumption levels (see also Table 2). If we assume an endured lockdown of 5 months, not only the crisis becomes more severe, with a GDP reduction of -5.5 percent, but also welfare losses spreads wider across household groups (see right graph figure 5). Now the poorest household, i.e. borrowing constraint people, have welfare losses between -1.5 and -3 percent of steady state consumption depending on whether their workplaces are affected or not. In contrast, superrich households, i.e. people at the top end of the wealth distribution, in the non-affected sector still benefit from the shutdown, which again increases slightly once the government provides financial aid.

\subsection{A partial lockdown in an 'open economy'}

In the 'small open economy' the similar wage and interest rate mechanisms are at work as in the 'closed economy': Thus, affected households borrow massively against the negative income effects of the lockdown shock. However, in contrast to the closed economy with access to international financial markets, increasing debt of affected agents meets interest-inelastic demand and supply of international lenders and debtors. Domestic agents in the non-affected sector are no longer forced to hold a positive asset position anymore (see Figure 6).
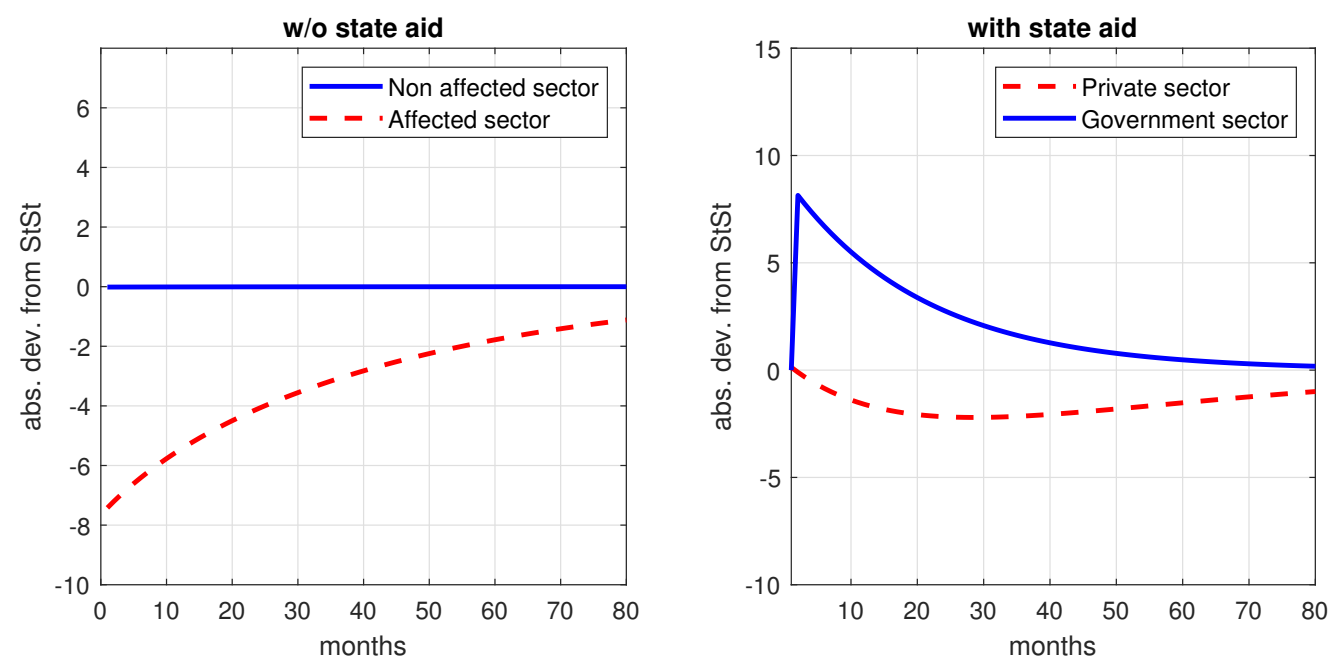

Figure 6: Asset positions after a partial lockdown in an 'open economy' $w / o$ (left) and with 'state aid program' (right)

Thus, the interest rate remains constant, such that positive wealth effects for rich households - no matter if they work in the affected or in the non-affected sector - are no longer possible (See figure 7). On the positive side, welfare losses of poor agents are smaller, because they have to bear lower borrowing costs. However, poor agents still suffer the largest welfare losses, also because the strongly decreasing wage has a larger share of their total income. In total, the aggregate welfare effects are 6.7 percent smaller than in the closed economy counterpart and the distribution of the welfare effects is more homogenous (see Table 2). 
Finally, we analyze the distributive effects of the 'state aid program' in the 'small open economy' case, where agents have access to international financial markets. Similar to the closed economy case and thus not surprisingly, government financial aid per se dampens the negative economic and distributive effects. Aggregated across all agents, the 'state aid program' dampens aggregate welfare losses in the baseline calibration by 9.5 percent and 12 percent in case of a severe crisis.
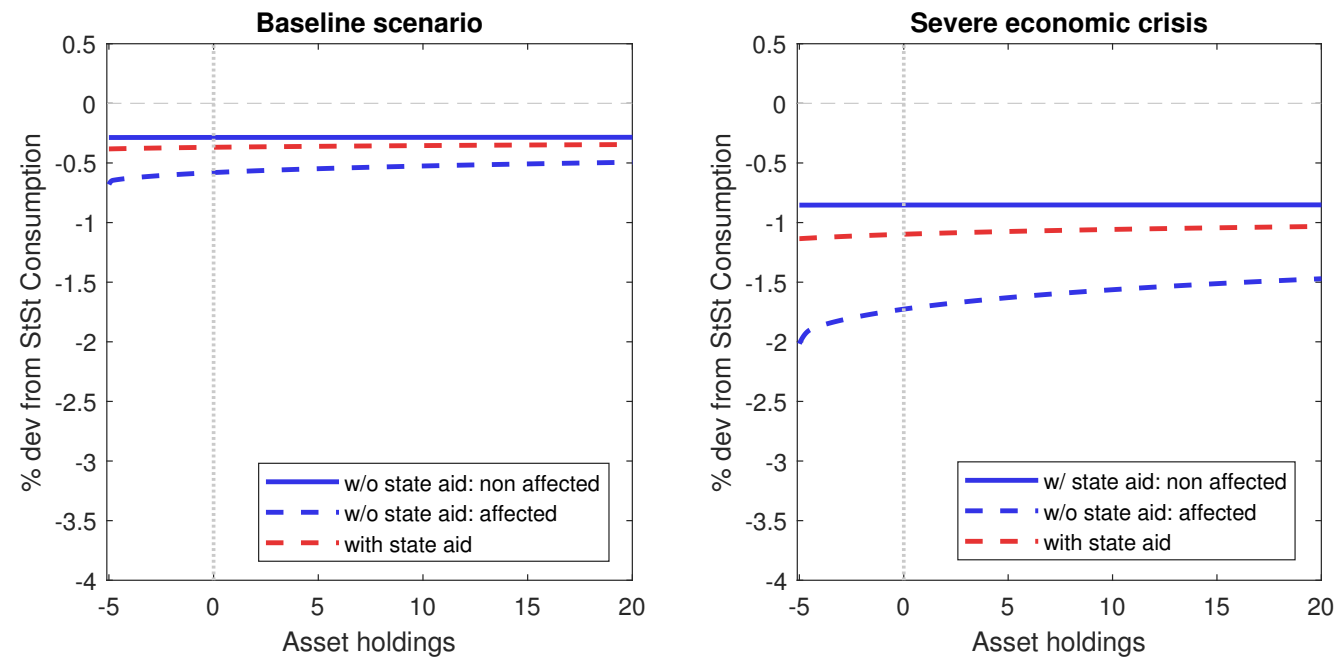

Figure 7: Welfare effects of a partial lockdown in an 'open economy', baseline calibration (left) and severe economic crisis calibration (right)

Moreover, compared to the closed economy the total welfare losses are considerably smaller. Thus, the rescue package is more efficient. The reason is twofold: First, in an open economy setup government can finance the 'stat aid program' via less interest rates payments in the future, which results in lower future tax payments as in the closed economy. Second, in the open economy, debt financing does not increase the welfare of the rich.

In figure 8 , we summarize the welfare effects for the poorest, mean and superrich household for all simulated scenarios separated by affected (left-hand) and non-affected sectors (right-hand). The total column reflects the relative welfare gain compared to the 'closed economy'-'no state aid' case. Each differently colored part of the column indicates the relative welfare gains of either implementing a the 'state aid program', having access to international financial markets in the 'open economy' setup or both together. For example, the lockdown-related welfare loss of poorest households working in the affected sector (first column, left graph) can be reduced by more than 0.7 percentage points (in terms of steady state consumption) once private and public households can borrow internationally ('open economy') and the government provides 'state aid'. By comparing the results, we summarize the following relevant findings:

First, negative welfare effects of a lockdown shock are inevitable, thus stabilization policy of the government should mainly concentrate on the distributional effects. The 'state aid program' (yellow) reduces large parts of the welfare losses of workers across all income groups in the affected sectors. Within the non-affected sectors most workers 

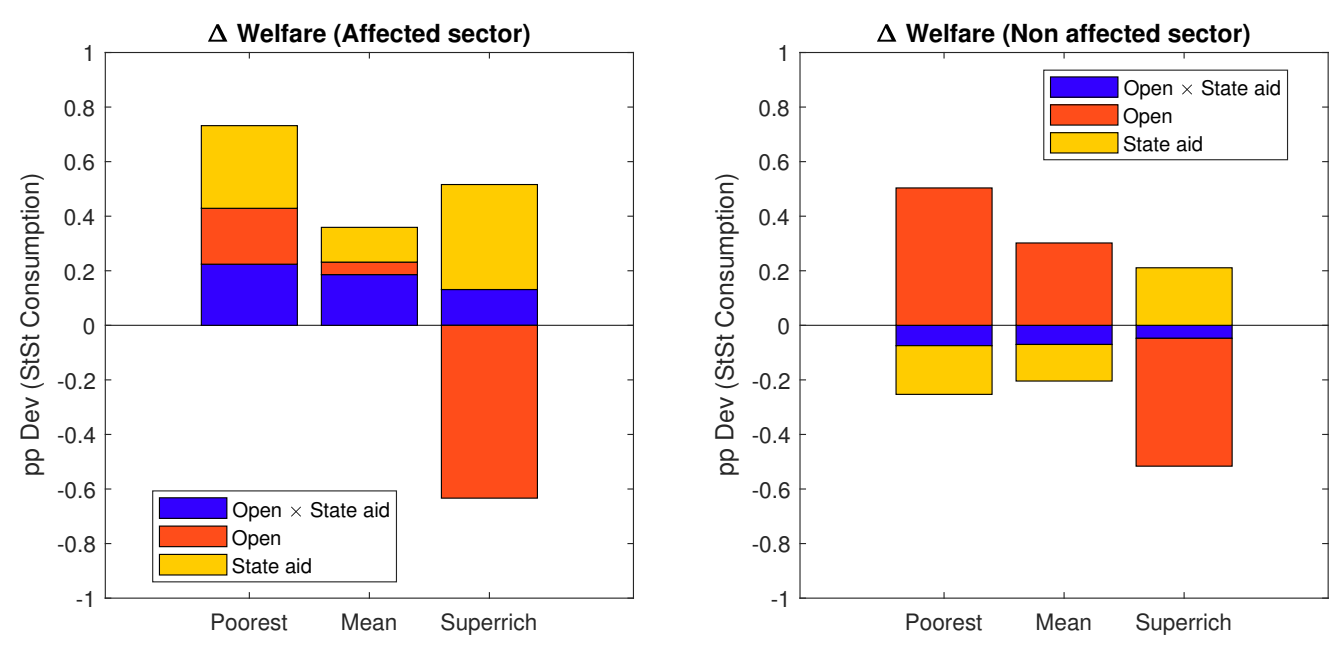

Figure 8: Welfare differentials for poorest, mean and superrich households compared to the 'closed economy' 'no state aid' case by sector

face welfare losses from the government aid package because they are now subject to economic losses through tax payments. However, superrich households no matter in which sector still benefit more than the average household.

Second, access to international financial markets is key to shift relative welfare gains from superrich to poorer households in both sectors (red). As we have already seen, superrich may even profit from the partial lockdown if a country has no access to international financial markets, because they benefit from the strong interest rate increase. Once the country has access to international financial markets, the relative welfare gains for the superrich diminishes. But those households even benefit more from a 'state aid program' in the 'open economy' setup (blue and yellow column) than e.g. the mean household.

\subsection{Parameter robustness}

In order to assess the robustness of our model results we analyze specific parameter changes. We focus on parameters that determine the characteristics of the sectoral lockdown shock. In our 'baseline' calibration with a month long lockdown and an immediate restart of the economy the model predicts a moderate GDP reduction of -1.1 percent and an increase of the debt to GDP ratio of 1.2 percentage points. In relation to the projections and to first empirical evidence these numbers seem to be relatively low (See Table 5 in the Appendix). However, in our model we concentrate on the distributional and welfare effects of supply-side lockdown shocks. Particularly, we do not consider further negative impacts through, e.g. preference changes, sectoral spillovers, global demand disruptions and uncertainty-related lower investment demand. These mainly demand-side effects would presumably result in larger and more persistent production losses. ${ }^{17}$ With this in mind and in order to compare our distributive implications for

\footnotetext{
${ }^{17}$ See e.g. Guerrieri et al. (2020).
} 
alternative scenarios we change the restrictiveness of the lockdown, the length of the lockdown and the elasticity of substitution between goods produced either in the affected or non-effected sector. Thereby, our lockdown model is able to generate similar GDP dynamics for 2020 and 2021 as projected by the joint economic forecast of German research institutes (see Figure 9 in Appendix).

\begin{tabular}{ll|c|c|c|c|c}
\hline \hline & & \multicolumn{5}{|c}{ 'Closed economy' } \\
\cline { 2 - 7 } & & (1) Baseline & $(2) A_{2}^{\prime}=0.1$ & $(3) \mu=0.67$ & $(4) t_{l}=5$ & (5) $t_{l}=5, \mu=0.67$ \\
\hline 'no state aid' & $\bar{\Delta}$ & -.45 & -1.83 & -1.51 & -1.68 & -1.99 \\
& $\bar{\Delta}_{N A}$ & -.29 & -1.33 & -1.02 & -1.10 & -.29 \\
& $\bar{\Delta}_{A}$ & -.67 & -2.55 & -2.22 & -2.52 & -4.44 \\
\hline 'state aid' & $\bar{\Delta}$ & -.41 & -1.58 & -1.77 & -1.57 & -1.53 \\
\hline GDP & $\%$ & -1.13 & -1.83 & -1.89 & -4.49 & -10.56 \\
Debt/GDP & $\%$ & 1.20 & 2.34 & 2.44 & 5.07 & 14.16 \\
\hline \hline & & \multicolumn{5}{|c}{ 'Open economy' } \\
\cline { 2 - 7 } & $(1)$ Baseline & $(2) A_{2}^{\prime}=0.1$ & $(3) \mu=0.67$ & $(4) t_{l}=5$ & $(5) t_{l}=5, \mu=0.67$ \\
\hline 'no state aid' & $\bar{\Delta}$ & -.42 & -.72 & -.36 & -1.64 & -1.73 \\
& $\bar{\Delta}_{N A}$ & -.28 & -.47 & -.11 & -1.11 & -.32 \\
& $\bar{\Delta}_{A}$ & -.63 & -1.08 & -.72 & -2.41 & -3.78 \\
\hline 'state aid' & $\bar{\Delta}$ & -.38 & -.62 & -.29 & -1.44 & -1.27 \\
\hline GDP & $\%$ & -.95 & -1.55 & -1.75 & -3.64 & -10.25 \\
Debt/GDP & $\%$ & .93 & 1.53 & 1.74 & 3.46 & 10.21 \\
\hline \hline
\end{tabular}

Table 2: Welfare effects of a partial lockdown

$\Delta$ denotes percentage welfare loss in terms of steady state consumption

Under a more restrictive lockdown production reduces by 90 percent compared to 70 percent in the baseline, GDP drops 0.7 percentage lower and debt-to-GDP ratio is 1.1 percentage points higher than in the baseline. The aggregate welfare losses increase by 1.4 percentage points (second column in Table 2.).

In a second alternative scenario we increase the elasticity of intratemporal substitution, which measures the complementarity between goods produced in the affected and in the non-affected sector (third column in Table 2). If the produced goods become better substitutable $(\mu=0.67)$, the GDP growth and debt-to-GDP effects are similar as in the more restrictive scenario, but welfare losses are significantly less pronounced.

Another relevant parameter is the duration of the lockdown. In the baseline scenario we assume one month, but recent observations show that the shutdown will endure longer, not for every branch but for some, e.g. restaurants, travel, bars. Assuming the scenario of an endured lockdown we prolong the shutdown up to 5 months (fourth column in Table 2). Under this scenario GDP growth reduces by -4.5 percent and debtto-GDP ratio increases by 5.1 percentage points. The additional aggregate welfare losses of 1.2 percentage points compared with the baseline are tremendous.

Finally, we simulate a combination of longer lockdown and higher substitutability (fifth column in Table 2). This calibration creates a massive recession: GDP reduces by 10.6 percent, debt-to-GDP ratio increases by 14 percentage points, and welfare losses, especially in the affected sectors are large. 
Regarding the welfare effects from the 'state aid program' we can summarize, that the government mitigates the negative welfare effects across all scenarios in the closed economy setup. However, the extent of this mitigation increases with the severity of the recession. While in the baseline, government financial aid dampens welfare losses by 8 percent, in the more restrictive (column 4) and the massive recession scenario (column 5) the welfare losses diminish by 14 and 23 percent once the government provides financial aid.

In the small open economy setup, the welfare losses are generally lower. Again, the stabilizing effects through borrowing internationally increases with the severity of the crisis. In the baseline scenario financial openness reduces the aggregate welfare losses by 6.7 percent and 13 percent in case of the massive recession scenario (column 5 ).

Finally, the robustness calculations confirm our findings that 'state aid' is more effective in terms of stabilization once the country has access to international financial markets. Compared to the 'no state aid' baseline case the government dampens welfare losses by 9.5 percent in the 'open economy' setup. In the massive recession scenario government financial aid mitigates even 26.6 percent of aggregate welfare losses.

\section{Conclusion}

In our paper we contribute to the macroeconomic COVID-19 literature by analyzing the distributional effects of lockdown shocks and welfare effects of compensatory measures of the government. We use a two-sector incomplete markets model with heterogenous agents and a partial lockdown shock. The aim of the paper is to derive the welfare effects for different households distinguished by the affected and the non-affected sectors and to analyze the effects of the 'state aid program'. We compare our baseline results from a 'closed economy', where borrowing is only possible between sectors, with an 'open economy' setup, where agents can borrow internationally.

While negative aggregate welfare effects of the lockdown are unavoidable, the size of aggregate welfare effects as well as the distribution of the welfare effects across agents turn out to depend on the specific economic environment of the affected economy as well as the response of the government to the shock.

We calibrate the model to German data and find that neither government financial aid policies nor borrowing at international financial markets can fully compensate welfare losses, especially poor agents working in affected sectors loose. Contrary, superrich households could even profit from the COVID-19 shock.

However, a 'state aid program' reduces the welfare losses by workers of all wealth groups in the affected sectors. In contrast, in the non-affected sectors most agents face relative welfare losses from the 'state aid program' due to compensatory tax increases. However, superrich households no matter in which sector they work still benefit more than the average households from the 'state aid program'. Access to international financial markets is key to shift relative welfare gains from superrich to poorer households in both sectors. Once the country has access to open markets, the welfare gains for superrich agents diminish. 
Our results point towards two aspects of the recent debate of how to stabilize the economy in Germany and in Europe.

First, in case of Germany, a 'state aid program' for workers stabilizes the economy: The aggregate welfare losses dampens by 7 percent converted in steady-state consumption when assuming a one month lockdown followed by an immediate restart. The mitigation increases with the severity of the lockdown. However, the superrich - no matter if they work in the affected or in the non-affected sector - benefit from the program more than mean households. This noteworthy result may should be considered when it comes to implementing a detailed consolidation policy design, e.g. redesigning the tax schedule.

Second, from the perspective of European countries with rather limited access to international financial markets and less stable government budget situations such that only relatively small financial aid packages can be provided. Here, the COVID-19 shock will not only reduce GDP by a higher amount, but also increases inequality significantly. Thus, the welfare losses will be much higher than in countries that have easier access to international financial markets, i.e. borrowing internationally is less costly. Without other instruments, e.g. a common European stabilization mechanism partly financed by debt, those countries will face raising inequality and large welfare losses. 


\section{References}

Aiyagari, S. Rao. 1994. "Uninsured idiosyncratic risk and aggregate saving." The Quarterly Journal of Economics 109 (3):659-684.

Atkeson, Andrew. 2020. "What will be the economic impact of COVID-19 in the US? Rough estimates of disease scenarios." NBER Working Paper 26867, National Bureau of Economic Research.

Baldwin, Richard and Beatrice Weder di Mauro. 2020. Economics in the time of COVID-19. CEPR Press, 1 ed.

Bayer, C., B. Born, R. Luetticke, and G. Müller. 2020. "The Coronavirus stimulus package: How large is the transfer multiplier." CEPR Working Paper 14600, Center for Economic and Policy Research.

Bayer, C. and M. Kuhn. 2020. "Intergenerational ties and case fatality rates: A crosscountry analysis." CEPR Press.

BMWi. 2020. "Spring Projection of the German Government." Federal Ministry of Economic Affairs and Energy.

Carroll, C. 2005. "The method of endogenous gridpoints for solving dynamic stochastic optimization problem." Economics Letters 91 (3):312-320.

CEPR. 2020. "Covid economics: Vetted and real-time papers." Series. CEPR Press.

Destatis. 2020. "Volkswirtschaftliche Gesamtrechnungen - Input-Output-Rechnungen nach 12 Gütergruppen." Revision 2019.

Eichenbaum, Martin S., Sergio Rebelo, and Mathias Trabandt. 2020a. "The macroeconomics of epidemics." NBER Working Paper 26882, National Bureau of Economic Research.

—. 2020b. "The macroeconomics of testing and quarantining."

EU. 2020. "Spring 2020 Economic Forecast.” EU Commission.

Federal Employment Agency. 2020. "Monthly short time work - time series."

Ferguson, N. M. et al. 2020. "Impact of non-pharmaceutical interventions (NPIs) to reduce COVID-19 mortality and healthcare demand." Imperial College COVID-19 Response Team.

Furceri, Davide, Prakash Loungani, Jonathan D. Ostry, and Pietro Pizzuto. 2020. "Will COVID-19 affect inequality? Evidence from past pandemics." Covid Economics 1 (12):138-158.

German Council of Economic Experts. 2020. "The economic outlook in the Coronavirus pandemics." Report. 
German Economic Research Institutes. 2020. “Joint economic forecast." Report.

Glover, A., J. Heathcote, D. Krueger, and J.-V. Ríos-Rull. 2020. "Health versus wealth: On the distributional effects of controlling a pandemic." PIER Working Paper 20-014.

Guerrieri, Veronica, Guido Lorenzoni, Ludwig Straub, and Ivan Werning. 2020. "Macroeconomic implications of COVID-19: Can negative supply shocks cause demand shortages?" NBER Working Paper 26918, National Bureau of Economic Research.

Huggett, Mark. 1993. "The risk-free rate in heterogeneous-agent incomplete-insurance economies." Journal of Economic Dynamics and Control 17 (5-6):953-969.

ifo Institute. 2020. "ifo business climate index plunges to historic low." Results of the ifo Business Survey for April 2020.

IMF. 2020. "World Economic Outlook." Report.

Kaplan, G. and Moll, B. and Violante, G. 2020. "Pandemics according to HANK."

Kholodilin, Konstantin and Malte Rieth. 2020. "Viral shocks to the world economy." Diw discussion paper 1861, DIW Berlin.

Krueger, D., H. Uhlig, and Xie T. 2020. "Macroeconomic dynamics and reallocation in an epidemic." CEPR Working Paper 14607.

Working Party on Tax Revenue Estimates. 2020. "Tax estimation results May 2020.” 


\section{Appendix}

\subsection{Data and Tables}

\begin{tabular}{lc}
\hline Sector & Consumption Share \\
\hline Sports, Entertainment and Culture (Services and Production) & 11.1 \\
Hotels and Resturants & 2.2 \\
Traffic and Mobility & 14.0 \\
Other Services (Hairdressing) & 1.0 \\
Other Production & 1.9 \\
Clothes and Wearings & 4.5 \\
Furnishing, Household Equipment & 6.5 \\
\hline Affected sector & 41.2 \\
\hline Alcoholics & 3.2 \\
Housing, Water, Gas, Energy & 23.6 \\
Health & 5.3 \\
News and Media & 2.3 \\
Education & 1.0 \\
Other Services (i.e. Banking and Insurance) & 9.4 \\
Food and Beverages & 10.7 \\
\hline Non-affected sector & 58.8 \\
\hline
\end{tabular}

Table 3: Consumption shares - Affected and non-effected sectors in Germany

Source: German Economic Research Institutes (2020)

\begin{tabular}{lcc}
\hline Sector & lockdown & easing \\
\hline Industry & -15 & 13 \\
Energy & -10 & 13 \\
Trade & -17 & 5 \\
Consulting & -20 & 24 \\
Other Services & -25 & 22 \\
Housing & -3 & 4 \\
Information & -3 & 2 \\
\hline Affected Sector & -21 & 19 \\
\hline
\end{tabular}

Table 4: Production growth in affected and non-affected branches in Germany - 1 month lockdown, quarterly rates

Source: German Economic Research Institutes (2020) 


\begin{tabular}{lccc}
\hline Institutions & 2019 & 2020 & 2021 \\
\hline Council of Economic Experts & 0.6 & -2.8 & 3.7 \\
Joint Economic Forecast & 0.6 & -4.2 & 5.8 \\
IMF & 0.6 & -7.0 & 5.2 \\
Ministry of Economic Affairs & 0.6 & -6.3 & 5.2 \\
EU Commission & 0.6 & -6.5 & 5.9 \\
\hline
\end{tabular}

Table 5: Selected annual GDP Forecasts

Source: German Council of Economic Experts (2020), German Economic Research Institutes (2020), IMF (2020), BMWi (2020), EU (2020)

\subsection{Figures}

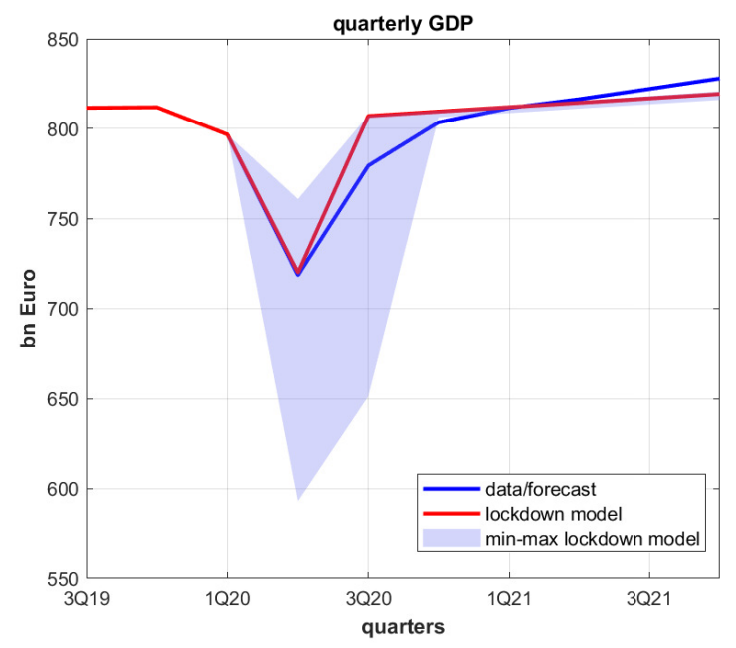

Figure 9: (Estimated) Data vs. Model - Germany 1Q2019-4Q2021

Source: German Economic Research Institutes (2020) 